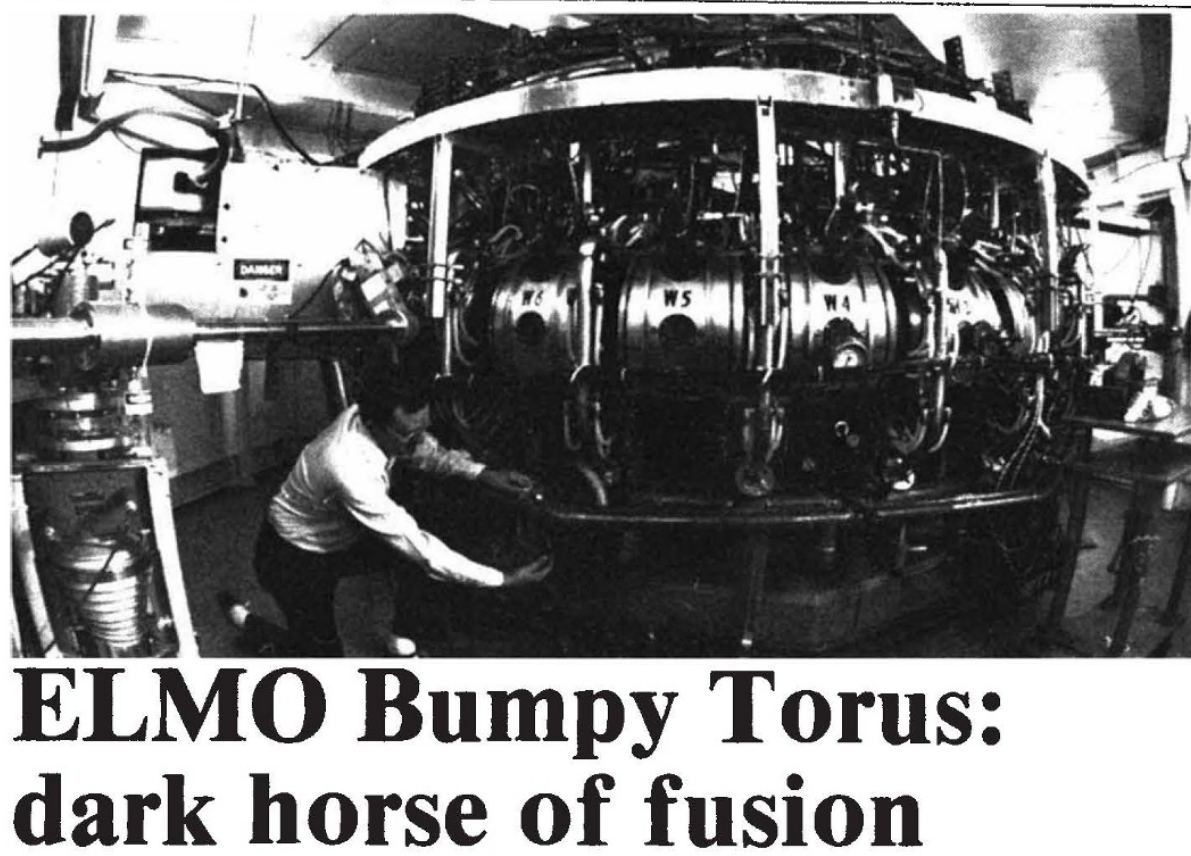

To most nuclear engineers, magnetic confinement fusion technology tends to be identified with the familiar doughnut shape of the Russian-designed Tokamak, which gained acceptance over US designs in the early 1960s, and of which 40 are now in experimental operation world wide.

But both Tokamak technology and the less familiar mirror confinement techniques still face many unanswered questions. And two years ago an ad hoc review committee appointed by the US Department of Energy recommended that, in the light of such uncertainties, increased support be given to alternative designs.

Two contenders emerged from a further review. One was the reversed field pinch, an adaptation of the Tokamak design; the other was a device that had been worked on at the Oak Ridge National Laboratory since the 1960s, known as the ELMO Bumpy Torus (EBT). A hybrid between the Tokamak and mirror designs, the EBT was subsequently selected for development to a point where it can be compared directly to the operation of existing Tokamaks.

Last Autumn, four industrial consortia - headed by Westinghouse, Grumman, McDonnell-Douglas and Ebasco produced separate plans for a 'proof-ofprinciple' EBT. These were amalgamated into a single design. And earlier this month the four consortia were asked to bid competitively for what has become known as the EBT-P.

The Bumpy Torus is based on a discovery made by a team headed by $\mathrm{Dr}$ Ray Dandl at Oak Ridge in the 1960s. When magnetic 'mirrors' produced by current-carrying coils are used at either end of a cylindrical cavity to keep plasma particles from escaping, and the plasma is heated by radio waves at the electron cyclotron frequency, a ring of electrons is found to form around the plasma at the mid-point between the two end coils.

This ring is of sufficiently high energy to keep the plasma away from the walls of the cylinder, necessary because of its high temperature. And the ring remains in place even when the end coils are inclined at an angle of 15 degrees to each other.

Putting 24 such cylindrical modules together end-to-end results in a torus. It is called 'bumpy' because the magnetic field is narrower between the mirrors than in the centre of each segment. No-one except Ray Dandl knows why it is called ELMO and he is not saying.

So far two experimental EBTs have been built at Oak Ridge (and one in Japan), and both have operated successfully according to theoretical predictions.

Operationally the EBT has two important advantages over the Tokamak, according to Dr John Sheffield, head of the Experimental Confinment Section at Oak Ridge. The first is that it operates in a steady state, rather than the pulsed mode of the Tokamak.

The second is that, without the complexity of the interlocking coils required by the Tokamak design - and the engineering difficulties caused by their magnetic interaction - construction problems could be considerably less.

Whether these advantages are sufficient to overcome the relative lack of knowledge about the EBT compared to the extensive amount already known about the behaviour of Tokamaks remains to be seen. At present EBT technology is about ten years behind; and with Congress pushing the DOE hard for the construction of an engineering test facility (ETF) for the

Furthermore, promising results are being reported from tests with mirror confinment devices at the Lawrence Livermore Laboratory, three to five years behind the Tokamak but still ahead of the EBT. DOE officials are considering putting a request for $\$ 100$ million to construct a new mirror test facility in the 1982 budget. Tokamak, it will be difficult to catch up.

\section{Senate approves patent changes}

HOPES are high among US research universities that, following a six-year campaign, the US Congress will soon pass legislation boosting their rights to benefit directly from the results of research carried out with federal funds.

Last week the Senate passed a bill which would allow universities and small businesses, under certain defined conditions, to license any patents arising from such research. Similar measures are already under active consideration in the House of Representatives. And given the large majority that voted for the Senate measure, university lobbyists in Washington are confident that they will have a new law on the books by the end of the year.

Revision to the patent law has been a cornerstone of attempts both in Congress and by the Administration to tackle the recent drop in industrial productivity and an apparent decline in the rate of technological innovation. Both are claimed to contribute to the nation's economic problems. And both, it is argued, could be reversed by assisting the flow of research results into the market-place.

A variety of bills has been introduced into both legislative bodies over the past year. Some, such as a bill passed by a subcommittee of the House Science and Technology Committee three weeks ago, have recommended that patent rights be awarded to anyone carrying out federallysponsored research.

The universities, however, fearful that too broad an approach might fail to win sufficient support, have put their efforts behind a more limited bill introduced by senators Birch Bayh and Robert Dole which gives patent rights to universities and small businesses, but excludes large businesses.

Six weeks ago, when the bill reached the floor of the Senate, it was threatened with a filibuster by Senator Russell Long, who claimed that liberalising the patent laws would encourage monopoly practices and discourage competition. The bill was subsequently withdrawn from debate.

When offered last Thursday, Senator Long spoke strongly against the bill. But he did not offer any amendments that might have killed the measure, and the final vote was 91 to 4 in favour, an indication of the depth of support.

Under the Senate Bill, a university will have the exclusive rights to a 17 -year patent on federally sponsored research results, providing it illustrates that it has the institutional means to license the patent. The bill contains a provision that if the patent proves commercially successful, the government should be paid back for the costs of the research.

David Dickson 